\title{
Smart Services Classification Framework
}

\author{
Tatiana Gavrilova, Liudmila \\ Kokoulina \\ Graduate School of Management, \\ St. Petersburg University, \\ Volkhovsky per. 1-3, St. \\ Petersburg, Russia \\ Email: \{gavrilova, \\ l.kokoulina\}@gsom.pu.ru
}

\begin{abstract}
The main goal of the study is development of the classification framework of smart service attributes as a first step in developing methodology of smart services implementation for Enterprise Information Portal (EIP) maintenance. First, we analyze available definitions of the "smart services" concept and concepts related to it: smart services are based on the idea of co-creation of value and rely on machine intelligence in connected systems. Second, we describe attributes of EIP services. Finally, we propose a new extended approach of the smart service attributes classification based on the list of characteristics of the EIP services. Our results contribute to the field of smart service research as well as to EIPrelated studies both for academics and practitioners, as the proposed classification framework could serve as a basis for creation of smart services typology for the purpose of EIP maintenance.
\end{abstract}

\section{INTRODUCTION}

$\mathrm{T}$ HE concept of smart services has been evolving for decades, however, the field of smart services is still appears to be under development [1]. Publications devoted to smart services usually analyze this phenomenon from the practical perspective. Still, there is a need of further theorizing and conceptualizing of smart service concept.

One of the promising directions of smart services implementation is creation of the smart service system for the Enterprise Information Portal support. Enterprise Information Portal (EIP) serves as a unique point of contact for users providing information and supporting business decisions. EIP maintenance includes such processes as knowledge elimination, new knowledge regulation, and support. Proper EIP maintenance requires highly skilled professionals, and not all organizations potentially interested in EIP implementation would therefore agree to this endeavor.

As a part of our project "Ontology-based INtelligent Services for the knowledge PORTals support (InS-PORT)" we develop a methodology of creation of smart service system which would help to maintain EIP. The purposes of this smart service system are to support knowledge base formation, to eliminate outdate or improper information, to support the process of new knowledge regulation. However, this task requires deep understanding of smart service capabilities and structure. To the authors` knowledge, there are no developed smart service classifications. As a first step in dealing with this problem, we developed a smart service attributes` classification which is present in this short paper.

Our study is important for the smart service research stream due to several reasons. First, classification of the emerging phenomena enhances a uniform and standardised terminology. Besides, the classification helps to understand the definition of the object of classification.

This paper is structured as follows. In the next section, theoretical background of the smart service phenomena is presented, the various definitions are discussed, and the purpose of classification is justified. In the subsequent section, the research methodology is described and classification scheme procedural model is given. Next section of the article introduces the research on Enterprise Information Portal. As the result of the study, the developed smart service attributes classification framework is described in the subsequent section. The paper ends with conclusion remarks, limitations and future research.

\section{REVIEW OF THE LITERATURE}

First, we analyze available definitions of the "smart services" concept and concepts related to it. Currently, there are very few peer-reviewed publications on this topic, and most of them do not provide any formal definitions. The majority of definitions are very general or ambiguous. For example, one of the top experts in the field, Paul P. Maglio introduces smart services as:

“... capable of self-detection, self-diagnostic, selfcorrective, or self-controlled functions through the incorporation of technologies for sensing, actuation, coordination, communication, control, and more" [2].

Some authors define smart services through description of their distinctive characteristics:

"Smart services are a wholly different animal from the service offerings of the past. To begin with, they are fundamentally preemptive rather than reactive or even proactive. Preemptive means your actions are based upon hard field intelligence; you launch a preemptive strike to head off an undesirable event when you have real-world evidence that the event is in the offing" [3].

Some authors claim that the use of term is often 
speculative, and that smart services are simply "...a marketing term to bring together various meanings of the term Service (economic, technical, political, business- and end user- oriented) with an adjective to make it sound clever" [4].

The term "service" is used here as "... a function of an enterprise that is exposed through various technologysupported channels, and is amenable to re-use and composition into larger services which add value" [4]. It is important to mention that recently a new research stream appeared, labelled as "service science". Service science takes most of its inspiration in recent IT services growth and has been actively supported by IBM. Scholars in this field are still providing rather general definitions of term "services" such as "... as clients and providers working together to transform some state, such as material goods, information goods, organizations, which bears some ownership relation to the client" [5]. The two main issues that are recognized as basic tenets of the service science are: (1) co-creation of value by producer and client and (2) broad implementation of information technology [2].

Furthermore, the term "smart" implies two main properties. First, it highlights anthropomorphic features of the smart service. For example, technology research company Gartner, Inc. claims that smart technologies are “... technologies that do what we thought only people could do. Do what we thought machines couldn't do" [6]. Second, term "smart" is usually related to artificial intelligence (i.e. intelligence of machine) " $[\ldots]$ because it is impractical to deploy humans to gather and analyze the real-time field data required, smart services depend on "machine intelligence" [3].

In summary, this short literature review demonstrates that there is no agreement on what "smart services" are. However, based on several streams of thought, we can identify some key elements which are common in most definitions and which can help to come up with the working definition. Those key elements are 1) machine intelligence, 2) connectedness and 3) value co-creation by client and provider of a service. Thus, smart services are based on the idea of co-creation of value and rely on machine intelligence in connected systems [1]. Speaking of the attempts of smart services classification, there are no visible papers on this subject.

\section{RESEARCH METHODOLOGY}

According to [7], 'a classification scheme consists of a set of characteristics which are suitable to classify objects of a specific application domain'. We have chosen a characteristic-based classification principle to develop a classification framework for smart service attributes since we suppose that the classification criteria might not necessarily be mutually disjunctive.

In our research, we follow the classification methodology proposed by [7]. This methodology suggests six general guidelines: completeness (the domain should be entirely covered by the classification scheme), precision (measure of detailing), consistency (lack of contradictions), extensibility (possibility to add or remove classes), user-friendliness (measure of how clear and understandable is the classification system), economic efficiency (related to costs associated with classification system implementation).
The procedural model to develop a classification scheme, described in [7], contains five phases: inception, elaborate characteristics, specify classification scheme, test, and use and maintenance. The first two stages include defining goals, conducting literature search in order to acquire a comprehensive set of potential characteristics. In our case, the literature concerning the EIP suggested the list of potential smart service classification characteristics. On the third stage the specification of the classification scheme was made, including defining principle of classification, selection and explanation of relevant characteristics, and defining relations between characteristics of the classification scheme. The last two phases ('test' and 'use and maintenance') are necessary for justification of the proposed classification framework, however, they are out of the scope of this paper and require further research.

\section{THE ENTERPRISE INFORMATION PORTAL}

As the main goal of our research is to create methodology for smart services implementation for the purpose of EIP maintenance, a review of theory behind both concepts is required. Therefore, we analyze the research stream devoted to EIP, smart services, and their communalities, in particular how smart services correlate with EIP services.

Smart services as a subject of studies lies on the intersection of the scientific and technological paradigms of the information systems, knowledge management systems (KMS), enterprise information portals, service systems and smart services.

At the roots of the artificial intelligence studies there was a concept of "knowledge-based system" (KBS) [8], while the notion of knowledge management system (KMS) appeared much later in the management literature, and it is much wider than KBS. KMS include methods and techniques for the search, analyses, structuring, systematization, update and distribution of the information [9].

The term "enterprise information portal" was introduced in 1998. EIP is comprised of applications allowing companies to disclose information stored internally and externally, and to give the users the unique point of access and personalized information necessary for the decision making process in business [10]. The body of literature of this subject distinguishes two types of enterprise information portals: enterprise information portals and enterprise knowledge portals. The former type includes portals with services of search, exchange and sharing of the information. The latter type includes services developed with artificial intelligence methods. For our purposes, we define knowledge portals as the systems of knowledge management with the system of access embedded through enterprise portal.

While considering only technological component of the service systems (which is a composition of the interconnected information systems) a property of intelligence is identified. The property of intelligence is achieved by knowledge base inclusion and/or context awareness obtained by sensors, dynamic scalability, etc. $[11 ; 12]$. This type of intelligence is closely related to big data analytics. Recently scholars have argued that as more software and embedded intelligence is integrated in industrial products and systems, predictive 
technologies based on big data will be used to predict product performance degradation, and autonomously manage and optimize product service needs [13].

Smart service systems could be considered as a subcategory of the intelligent systems. Smart service systems often have the following characteristics of the intelligent system:

- Self-configuration (or at least easy-triggered reconfiguration) $[14 ; 15]$,

- Proactive behaviour (capability for prognosis or preventive actions, as opposed to the reactive behaviour) [3],
- Interconnectedness and continuous interactivity with internal and external system elements [16].

However, there are no commonly accepted definitions of intelligent and smart services - these terms are still developing [3].

EIP structures are based on the service-oriented architecture where services are located in the separate module. Basic portals'services include information search and exchange, communication among users, collaborative usage of the information. The technical services, which support EIP, are presented in the table I.

TABLE I.

ENTERPRISE INFORMATION PORTAL SERVICES

\begin{tabular}{|c|c|c|}
\hline & Services & Functions \\
\hline \multirow{6}{*}{ 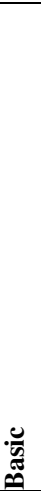 } & Communicational & $\begin{array}{l}\text { Information exchange, collaboration between users and portal`s } \\
\text { technical support group, realization of the modern voting and survey } \\
\text { tools }\end{array}$ \\
\hline & Informational & $\begin{array}{l}\text { Notification of users about changes of events in their spheres of } \\
\text { interests }\end{array}$ \\
\hline & Navigational & Information search, search efficiency optimization \\
\hline & $\begin{array}{l}\text { Analysis and visualization of the spatial } \\
\text { data }\end{array}$ & $\begin{array}{l}\text { Thematic search services, services of the analysis and visualization of } \\
\text { the spatial data (GIS portals) }\end{array}$ \\
\hline & Personalized/identification & $\begin{array}{l}\text { Identification, authorization and authentication of the portal`s users, } \\
\text { portal visualization adaptation based on the user`s preferences (e.g., } \\
\text { personal "cabinet" on the portal which stores the user`s profile and } \\
\text { preferred system settings) }\end{array}$ \\
\hline & Educational & Education of the employees \\
\hline \multirow{3}{*}{ 芦 } & Statistical & $\begin{array}{l}\text { Collection and analysis of the statistical information accumulated in } \\
\text { the portal }\end{array}$ \\
\hline & Audit & Logging of all actions included in the security system list \\
\hline & Monitoring & Monitoring service \\
\hline
\end{tabular}

\section{V.SMART SERVICES ATTRIBUTES CLASSIFICATION}

Based on the review of smart services capable to enhance EIP maintenance, the following main attributes are found:

- Types of the elements comprising the service [3],

- Structure of the interactions among different types of the elements comprising the service $[2 ; 3 ; 16 ; 17]$,

- The level of "intellectuality" or "intelligence" of the service $[11 ; 12 ; 14]$,

- Dynamic aspects of the service working process [3; 16],

- $\quad$ Types of the information available to the service [8; 18], etc.

- Physical realization of the service (Software-as-aService, Hybrid cloud, own servers of the organization).

Following the classification methodology proposed in [7], we divided these attributes into two sub-groups: basic or IT implemented, and abstract (not dependent on IT implementation).

Basic attributes reflect physical implementation of the smart services including organization of the elements and IT platform.

Abstract attributes point our actual functionality of the service important for the business goals achievement. Those include dynamic properties, degree of knowledge awareness, and type of intelligence. The description of the service types is provided in the table II. The final classification of the smart services is presented in Fig. 1. 
TABLE II.

SMART SERVICE ATTRIBUTES

\begin{tabular}{|c|c|c|c|}
\hline \multicolumn{3}{|c|}{ Smart service attributes } & Comment \\
\hline \multirow{3}{*}{ 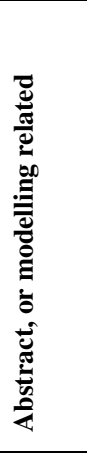 } & Dynamic properties & $\begin{array}{l}\text { Without modelling of the changing } \\
\text { environment; Past-based modelling; Stochastic } \\
\text { modelling. }\end{array}$ & $\begin{array}{l}\text { Modelling of the changing environment could be } \\
\text { based on the analysis of the past or the probabilistic } \\
\text { estimation of events. }\end{array}$ \\
\hline & Intelligence & Knowledge-based; Data-based; Content-based. & $\begin{array}{l}\text { Intelligence engine embedded in the smart service } \\
\text { could be based on content (letters, audio-, video-, } \\
\text { etc.), data (facts and features gathered from } \\
\text { observation, measurement, sensors, etc.), and } \\
\text { knowledge (rules and principles obtained from } \\
\text { experience or theory). }\end{array}$ \\
\hline & Knowledge awareness & $\begin{array}{l}\text { Context-oriented; Explicit knowledge; } \\
\text { Business intelligence. }\end{array}$ & $\begin{array}{l}\text { Smart services could be based on knowledge derived } \\
\text { from context (related to the user, environment, } \\
\text { situation [19]), explicit knowledge (archived } \\
\text { documents, charts), and business intelligence (OLAP } \\
\text { and decision support systems). }\end{array}$ \\
\hline \multirow{2}{*}{ 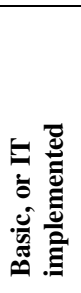 } & IT platform & $\begin{array}{l}\text { Mobile; SaaS; Hybrid cloud; Corporate } \\
\text { servers. }\end{array}$ & $\begin{array}{l}\text { The choice of IT platform depends on the goals of } \\
\text { the smart service: for internal purposes requiring } \\
\text { confidentiality corporate servers may be used, } \\
\text { however, SaaS and mobile platforms are gaining } \\
\text { popularity with growing reliability and security. }\end{array}$ \\
\hline & Elements & IT; People; Hybrid. & $\begin{array}{l}\text { As smart service usually is a socio-technical system, } \\
\text { the elements comprising it could be both IT (user- or } \\
\text { network- oriented) and people (users, analysts, } \\
\text { developers, support team). }\end{array}$ \\
\hline
\end{tabular}

In order to create a visualized from of smart service attributes classification, we illustrate our results with the mind map presented in fig. 1 .

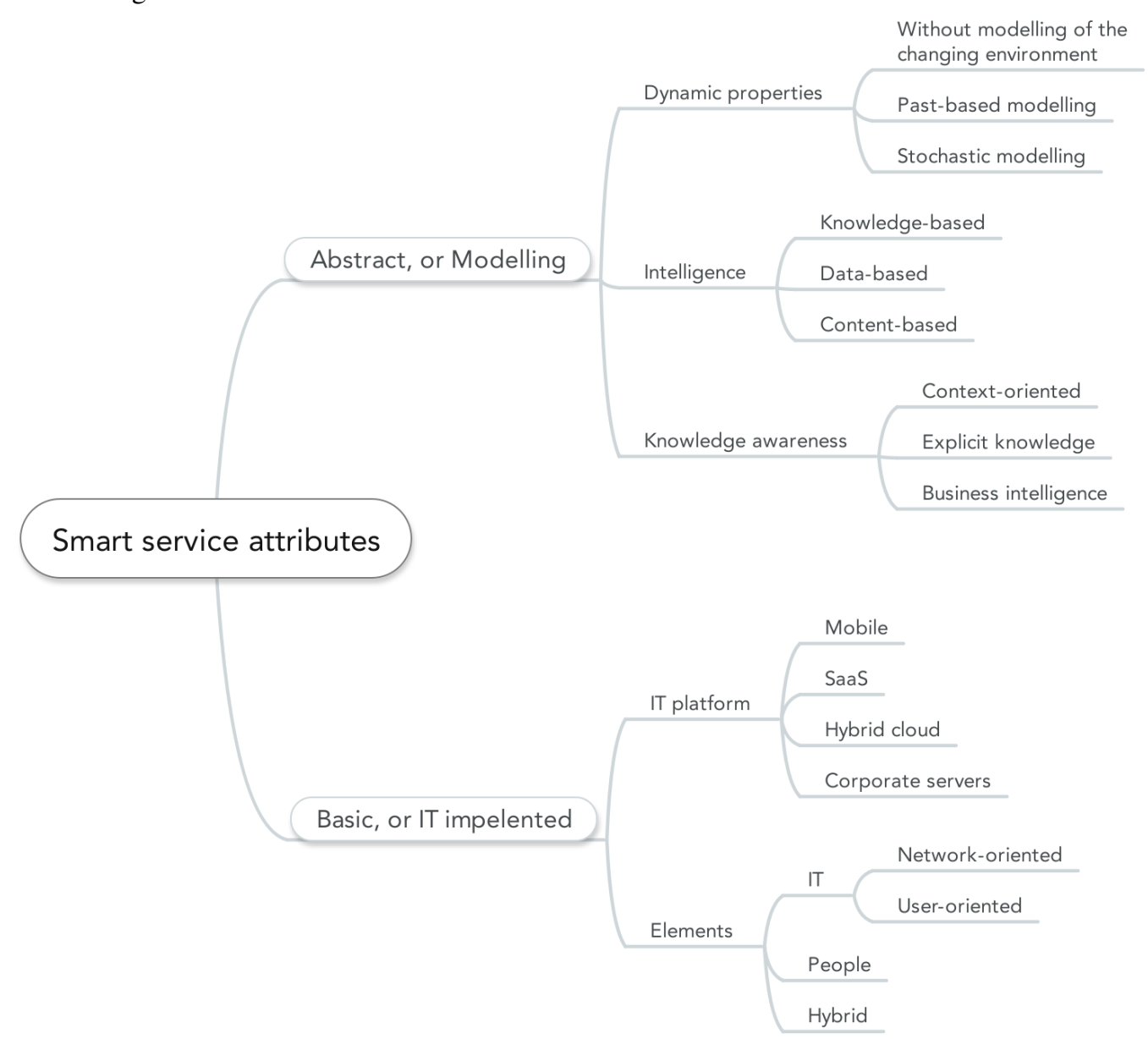

Fig. 1. Smart Services Attributes Classification 
The proposed classification framework serves as a starting point in developing methodology of smart services implementation for the purpose of EIP maintenance. However, this classification could be generalized to other cases of smart services implementation. Therefore, our results contribute to the theory behind smart service systems. Moreover, our classification will be helpful to practitioners interested in smart services implementation.

\section{Conclusion}

The main results of this study can be summarized as following. First, smart services are a relatively new concept that emerged because of progress in machine intelligence, global connectivity and big data. Second, the smart service system could be analyzed through the lenses of established knowledge management methods. The main contribution from this perspective is the development of new smart service attributes classification based on the characteristics derived from Enterprise Information Portal services analysis.

As of limitations of this research, the classification scheme creation procedure requires to test and revise the proposed scheme, therefore, more work is needed in order to test whether different smart services could be placed into it, to measure quality criteria (relevance, completeness), and to generate statistics of attributes' use.

Further research is required for the development of smart service typology and decision tree related to smart services implementation for the purpose of EIP maintenance and other contexts.

\section{ACKNOWLEDGMENT}

The research is supported by the grants of Russian Science Foundation (project No. 15-18-30048) and Russian Foundation for Basic Research (project No. 14-07-00294).

\section{REFERENCES}

[1] S. Vlasov, T. Gavrilova, "Smart services: state-of-the-art", in On-line proceedings of International conference "GSOM Emerging Markets Conference: Business and Government Perspectives”, St. Petersburg, 2014, pp. 523-530.

[2] P. P. Maglio, "Editorial column - Smart Service Systems", Service Science, vol. 6, no. 1, 2014, pp. 13-15. http://dx.doi.org/10. $1287 /$ serv.2014.0065
[3] G. Allmendinger, R. Lombreglia, "Four strategies for the age of smart services", Harvard Business Review, Sep. 2005, pp. 1-11.

[4] K. Duddy, "What Would Smart Services Look Like",in G. Feuerlicht \& W. Lamersdorf (Eds.), Service-Oriented Computing - ICSOC 2008 Workshops, vol. 5472, pp. 5-14. http://dx.doi.org/10.1007/978-3-64201247-1_2

[5] J. Spohrer, P. P. Maglio, "The Emergence of Service Science: Toward Systematic Service Innovations to Accelerate Co-Creation of Value", Production and Operations Management, vol. 17, no. 3, 2009, pp. 238-246. http://dx.doi.org/10.3401/poms.1080.0027

[6] T. Austin, "The Disruptive Era of Smart Machines Is Upon Us", Gartner, Inc., 2009.

[7] P. Fettke, P. Loos, "Classification of reference models: a methodology and its application", Information Systems and e-Business Management, vol. 1, 2003, pp. 35-53. http://dx.doi.org/10.1007/ BF02683509

[8] L. Shu-Hsien, "Expert system methodologies and applications-a decade review from 1995 to 2004", Expert Systems with Applications vol. 28 , no. 1,2005 , pp. 93-103. http://dx.doi.org/10.1016/ j.eswa.2004.08.003

[9] D. G. Schwartz, Encyclopedia of knowledge management, IGI Global, 2006.

[10] C. C. Shilakes and J. Tylman, Enterprise Information Portals, NY, Merrill Lynch, 1998.

[11] H. A. Simon, The sciences of the artificial, MIT Press, 1996

[12] R. A. Brooks, "Intelligence without representation", Artificial Intelligence vol. 47, no. 1, 1991, pp. 139-159. http://dx.doi.org/ 10.1016/0004-3702(91)90053-M

[13] J. Lee, H. Kao, S. Yang. "Service innovation and smart analytics for Industry 4.0 and big data environment", in Proc. of the 6th CIRP Conference on Industrial Product-Service Systems, 2014. http://dx.doi.org/10.1016/j.procir.2014.02.001

[14] S. Barile, F. Polese, "Smart service systems and viable service systems: Applying systems theory to service science", Service Science vol. 2, no. 1, 2010, pp. 21-40. http://dx.doi.org/10.1287/serv.2.1_2.21

[15] D. Tranfield, D. Denyer, P. Smart, "Towards a methodology for developing evidence-informed management knowledge by means of systematic review", British Journal of Management, vol. 14, no. 3, 2003, pp. 207-222. http://dx.doi.org/10.1111/1467-8551.00375

[16] N. Gershenfeld, R. Krikorian, D. Cohen, "The Internet of things", Scientific American, vol. 291, no. 4, 2004, p. 76. http://dx.doi.org/10.1038/scientificamerican1004-76

[17] A. Fano, A. Gershman, "The future of business services in the age of ubiquitous computing", Communications of the ACM vol. 45, no. 12 , 2002, pp. 83-87. http://dx.doi.org/10.1145/585597.585620

[18] M. Alavi, D. Leidner, "Review: Knowledge Management and Knowledge Management Systems: Conceptual Foundations and Research Issues", MIS Quarterly, vol. 25, no. 1, 2001, pp. 107-136. http://dx.doi.org/10.2307/3250961

[19] E. Pascalau, G. J. Nalepa, and K. Kluza, "Towards a Better Understanding of Context-Aware Applications", in Proc. of the 2013 Federated Conference on Computer Science and Information Systems, pp. 959-962. 